\title{
Cash Transfers and Health: Evidence from Tanzania
}

\section{David K. Evans, Brian Holtemeyer, and Katrina Kosec}

\begin{abstract}
How do cash transfers conditioned on health clinic visits and school attendance impact health-related outcomes? Examining the 2010 randomized introduction of a program in Tanzania, this paper finds nuanced impacts. An initial surge in clinic visits after 1.5 years-due to more visits by those already complying with program health conditions and by non-compliers-disappeared after 2.5 years, largely due to compliers reducing above-minimal visits. The study finds significant increases in take-up of health insurance and the likelihood of seeking treatment when ill. Health improvements were concentrated among children ages $0-5$ years rather than the elderly, and took time to materialize; the study finds no improvements after 1.5 years, but 0.76 fewer sick days per month after 2.5 years, suggesting the importance of looking beyond short-term impacts. Reductions in sick days were largest in villages with more baseline health workers per capita, consistent with improvements being sensitive to capacity constraints. These results are robust to adjustments for multiple hypothesis testing.
\end{abstract}

JEL classification: I18, I13, O12, H42

Keywords: cash transfers, health, government policy, health insurance

What role can cash transfers conditioned on health-seeking behavior play in alleviating the burden of poor health and limited access to formal medical care in Sub-Saharan Africa? Meta-analyses of programs from around the world suggest that conditional cash transfers (CCTs) can effectively alleviate extreme poverty and improve a range of human capital outcomes for children, at least during the period that the program is in place (Fiszbein and Schady 2009, Leroy et al. 2009, Independent Evaluation Group 2011). As the

David Evans is a senior economist in the Office of the Chief Economist for Africa at the World Bank; his email address is devans2@worldbank.org. Brian Holtemeyer is a research assistant in the Development Strategy and Governance Division at the International Food Policy Research Institute; his email address is b.holtemeyer@cgiar.org. Katrina Kosec is a senior research fellow in the Development Strategy and Governance Division at the International Food Policy Research Institute; her email address is k.kosec@cgiar.org. This work was undertaken as part of the CGIAR Research Program on Policies, Institutions, and Markets (PIM) led by the International Food Policy Research Institute (IFPRI). Funding support for this study was provided by the CGIAR Research Program on Policies, Institutions, and Markets (PIM), the International Initiative for Impact Evaluation (3ie), the Japan Social Development Fund (JSDF), the Spanish Impact Evaluation Fund (SIEF), and the Trust Fund for Environmentally and Socially Sustainable Development (TFESSD). The opinions expressed here belong to the authors, and do not necessarily reflect those of the World Bank, PIM, IFPRI, or the CGIAR. This study benefitted at various stages from experts at the World Bank, the International Food Policy Research Institute (IFPRI), the Tanzania Social Action Fund (TASAF) and elsewhere. At TASAF, the evaluation has been supported by the Executive Director Ladislaus Mwamanga, as well as the former Executive Director Servacius Likwelile. Amadeus Kamagenge has led TASAF input to the evaluation, and his entire team has contributed with substantive and logistical support. We are also grateful to Harold Alderman, Domenico Fanizza, Margaret Grosh, Melissa Hidrobo, Jef Leroy, David McKenzie, Berk Özler, Anna Popova, Dena Ringold, Shalini Roy, and Magnus Saxegaard for comments and helpful discussions. A supplementary online appendix to this article is available at The World Bank Economic Review website. 
evidence base has grown, countries have raced to adopt CCTs. Almost every country in Latin America now has a CCT program (Fiszbein and Schady 2009). Further, as of 2010, at least 14 countries in SubSaharan Africa had implemented a CCT program (Garcia and Moore 2012). While there is considerable evidence about the impacts of cash transfers-conditional and unconditional—on education outcomes, less is known about their impacts on health. A 2014 global review found 142 studies showing the impact of cash transfers on education outcomes but only 41 showing impacts on health and nutrition outcomes (Andrews et al. 2014).

Existing literature on the health impacts of cash transfers yields mixed results. There are several program types: unconditional cash transfers (UCTs) and CCTs conditioned on health, education, or both. Especially in Sub-Saharan Africa, conditions are often "soft" (e.g., warnings or small penalties are applied instead of withholding the full transfer), making the difference between CCTs and UCTs less stark (Garcia and Moore 2012). Relatedly, Paxson and Schady (2010) find that 28 percent of those participating in a UCT program in Ecuador thought conditions applied. However, even among cash transfer programs of the same type, there are often mixed impacts on health. Among UCTs, Haushofer and Shapiro (2016) find that a transfer program in Kenya improved mental health and increased food consumption. UCTs have been found to improve anthropometric outcomes for girls-though not boys-in South Africa (Duflo 2003, 2000). However, Paxson and Schady (2010) find null overall impacts of a UCT in Ecuador on cognitive, behavioral, and physical outcomes for children, with only those in the bottom expenditure quartile benefiting. And Handa et al. (2015) find no overall impacts of a UCT in Zambia on maternal health care utilization, with positive impacts only for women with better access to health services. CCTs conditioned on health have improved early childhood cognitive development (Macours et al. 2012) and child nutritional status (Maluccio and Flores 2005) in Nicaragua, improved child nutritional status for a select group of children (younger children from rural areas) in Colombia (Attanasio et al. 2005), and had null impacts in Brazil (Morris et al. 2004) and Honduras (Hoddinott 2010). Finally, several studies explicitly compare the impacts of UCTs versus CCTs. Akresh et al. (2014) find an increase in preventative health care visits for a CCT in Burkina Faso conditioned on education and health, but not for a comparison UCT arm. Robertson et al. (2013), in contrast, do not find systematic benefits of CCTs over UCTs in Zimbabwe. Similarly, for a CCT in Malawi conditioned on education, Baird et al. (2011) find that the UCT arm saw a greater reduction in teenage pregnancy among girls who had dropped out of school than did the CCT arm. And in the same study context, Baird et al. (2013) find greater mental health improvements and increases in usage of shoes among girls enrolled in school in the UCT arm than in the CCT arm. Given inconclusive findings in the literature on the health benefits of cash transfers, even among programs with similar designs, there is a need for greater understanding of the mechanisms through which cash transfers impact health.

We examine the impacts of a 2010 pilot CCT program in rural Tanzania on a range of health investments and outcomes. Among 80 study villages, 40 were randomly assigned to receive the CCT program, allowing us to estimate its causal impacts. Beneficiaries included both children aged 0-15 and elderly individuals aged 60 and older. Conditions of the program included visits to health clinics by young children aged 0-5 and by the elderly. Households were surveyed at baseline in 2009, again in 2011 after 18-21 months (about 1.5 years) of transfers, and finally in 2012 after 31-34 months (about 2.5 years) of transfers.

We find nuanced impacts of the CCT program. An initial surge in clinic visits after 1.5 years-due to more visits by both those already complying with program health conditions and non-compliersdisappeared after 2.5 years, largely due to compliers reducing above-minimal visits. We also find significant increases in take-up of health insurance. After 2.5 years, the program made households in treatment villages 36 percentage points more likely to participate in the government-run health insurance program (the Community Health Fund, or CHF) and raised the likelihood of financing treatment with health insurance by 16 percentage points. These impacts on health insurance are particularly 
interesting. Little previous work has examined the impact of cash transfers on participation in health insurance programs. ${ }^{1}$ The CCT additionally increased the likelihood of seeking treatment when ill. This latter result is important given recent research showing that timely clinic attendance when ill improves child health outcomes in Tanzania (Adhvaryu and Nyshadham 2015). We also find that the program led to significantly higher investments in preventative health measures, including an 18 percentage points increase in shoe ownership, which the public health community associates with lower exposure to helminths (Mascarini-Serra 2011, Birn and Solórzano 1999). Health improvements were concentrated among young children aged 0-5, with no detectable health improvements for elderly individuals similarly required to visit health clinics. Further, health improvements took time to materialize; we observe no improvements after 1.5 years, but 0.76 fewer sick days per month for those $0-5$ years old after 2.5 years. ${ }^{2}$ This suggests the importance of looking beyond very short-term impacts. Reductions in sick days were largest in villages with more baseline health workers per capita, consistent with improvements being sensitive to capacity constraints.

Overall, this evidence suggests a variety of mechanisms through which cash transfers may help to lift the burden of disease in Sub-Saharan Africa. We further show that these results are robust to adjustments for multiple hypothesis testing, estimation of linear as well as non-linear models, and both intent-to-treat and treatment on the treated estimates.

The remainder of the paper is organized as follows: Section 1 provides background information on health and the health care system in Tanzania as well as the health conditions of Tanzania's pilot CCT program. Section 2 describes the evaluation design, data, and outcomes of interest. Section 3 presents our empirical specification, the groups over which we examine heterogeneous treatment effects, balance tables showing the outcome of our randomization, and analysis of attrition. Section 4 characterizes our main empirical results and several robustness checks. Section 5 considers how our main impacts vary across different types of villages and households and what this implies for the mechanisms likely driving treatment effects. Section 6 concludes.

\section{Background}

\section{Health Care and Health in Rural Tanzania}

Tanzania is, in many respects, close to the Africa regional average in terms of health statistics. In 2012, 17.3 percent of the population contracted malaria versus 18.6 percent in Africa as a whole. Likewise, 3.1 percent of the population was HIV positive, versus 2.8 percent in Africa. Life expectancy at birth is 61 years versus 58 for Africa. Yet on some measures, Tanzania diverges significantly from the rest of the region. Its under-five mortality rate (5.4 percent of live births) is just over half that of Africa as a whole (9.5 percent). Its maternal mortality ratio is almost 20 percent lower than that of Africa. Yet the health workforce is weaker in Tanzania, with just 0.1 doctors and 2.4 nurses and midwives per 10,000 population (versus an average of 2.6 and 12.0, respectively, for Africa) (World Health Organization 2014).

Recent evidence from Tanzania demonstrates significant health improvements for children utilizing formal public health facilities (Adhvaryu and Nyshadham 2015). In the early 1990s, the Tanzanian government introduced a health insurance program called the Community Health Fund (CHF). It is a voluntary prepayment scheme; members pay a fixed annual fee of 5,000-10,000 Tanzanian shillings (\$3-\$6 US), ${ }^{3}$ depending on the region. Their entire family is then exempt from co-payments for visits to primary

1 Evidence from Mexico suggests that participation in a CCT program increased participants' awareness that they were enrolled in a health insurance program, but, in that case, actual enrollment was automatic upon enrollment in the cash transfer program (Biosca and Brown 2014).

2 When we refer to illness in the last month, we are in all cases referring to the last four weeks.

3 In 2009, the exchange rate ranged from 1,280 to 1,467 Tanzanian shillings per US dollar (Bank of Tanzania 2015). 
health care facilities (Marriott 2011). ${ }^{4}$ As Tanzania's CHF cross-subsidizes more costly to reach rural areas, it provides not only a risk-coping strategy but also significantly reduces total out-of-pocket health expenses by the poorest (such as CCT program beneficiaries in our study regions) (Ekman 2004; Mtei et al. 2007). This is especially so since the poorest are often credit constrained. Nonetheless, ten years after the introduction of the CHF, only ten percent of Tanzanians were enrolled; one of the reasons cited was inability to pay (Kamuzora and Gilson 2007).

\section{Pilot CCT Program}

Tanzania's pilot CCT program, implemented by the Tanzania Social Action Fund (TASAF, a social fund agency of the Tanzanian government), began delivering transfers in January of 2010. Its aims were to increase investments in health for young children (ages 0-5) and the elderly (ages 60 and over) and to increase educational investments for children aged 7-15. It operated in three districts-Bagamoyo $(70 \mathrm{~km}$ from Dar es Salaam), Chamwino $(500 \mathrm{~km})$, and Kibaha $(35 \mathrm{~km})$-where 80 eligible study villages were randomized into treatment and control groups of 40 villages each, stratified by village size and district. Randomization was carried out after identification of potential beneficiary households in all 80 villages. At village meetings held prior to randomization, TASAF communicated that control villages would receive the program in late 2012 and the program would continue in treatment villages. Median village size was 560 households at baseline, and every village had both a primary school and a public dispensary or health center, facilitating fulfillment of program conditions.

Treatment households received transfers every two months. Transfer amounts ranged from US \$12 to US \$36, depending on household size and composition. The CCT provided US \$3 per month for orphans and vulnerable children up to age 15 (approximately 50 percent of the food poverty line) and US \$6 per month for vulnerable individuals age 60 or older. In our follow-up surveys, the median size of the last transfer is US \$14.12; assuming six annual payments of this size, this is about 13 percent of annual household expenditures.

While CCT payments were made at the household level, conditions applied at the individual level. ${ }^{5}$ Children aged 0-5 had to visit a health clinic at least six times per year (the condition was relaxed for children aged 2-5 to two visits per year starting in 2012), ${ }^{6}$ those age 60 or over had to visit at least once per year, and no health conditions applied to others. Both preventive and curative visits fulfilled the health clinic visit conditions of the program, although visits had to be to a public facility (either a dispensary, health center, or hospital). There were no further restrictions on the timing of visits nor on the services to be received. Children aged 7-15 had to enroll in school and maintain an 80 percent attendance record.

TASAF worked with an elected community management committee (CMC) in each village to select beneficiary households. ${ }^{7}$ The CMC surveyed the poorest half of households, collecting data on eight household characteristics: roof material, light supply, water supply, type of toilet, ownership of four different assets (vehicle/motorcycle, radio, iron, poultry), number of windows on the house, household size, and number of meals eaten per day. TASAF then carried out a proxy means test to propose a ranking of

4 Up to seven family members are exempt from co-payments, although tests and medications are subject to fees. Upon introduction of the CHF, child and maternal health services were already exempt from co-payments according to official government policy (Babbel 2012).

5 We lack administrative data on compliance with conditions. However, in each follow-up survey, we asked: "[For your last transfer payment,] did you receive less money than you usually get?" and "What do you think was the reason?" At midline and endline respectively, 1.9 and 3.0 percent of treatment households reported receiving less than usual for a reason related to not meeting conditions.

6 As our endline survey was carried out during August-October 2012, we define compliance with clinic visit conditions at endline for two- to five-year-olds as having two or more clinic visits in the last year.

7 CMC elections occurred at village meetings; 10-14 members were elected with secret ballots. To run, a candidate had to have received financial training and have successfully managed a past TASAF-supported project. 
households by poverty level for CMC and village leader approval. On average, 23 percent of households became beneficiaries.

\section{Evaluation Design and Data}

\section{Evaluation Design}

We evaluate the impacts of the CCT program using three waves of data on beneficiaries and would-be beneficiaries. Table 1 presents the chronology of the program and impact evaluation. A baseline survey was carried out during January-May 2009, and payments began in January 2010. A midline survey was conducted during July-September 2011 (18-21 months after transfers began), and an endline survey was conducted during August-October 2012 (31-34 months after transfers began). The baseline survey included 1,764 households (a subset of beneficiary households) comprised of 6,918 individuals. The quantitative data collection was supplemented by two rounds of qualitative data collection (following the midline and endline surveys) employing focus group discussions and in-depth interviews.

Table 1. Timeline of CCT Program and Impact Evaluation

\begin{tabular}{|c|c|}
\hline Timing & Activity \\
\hline November 2007 - September 2008 & Program design \\
\hline September - November 2008 & Sensitization at regional, district, ward, and community levels \\
\hline January - May 2009 & Baseline survey \\
\hline September - October 2009 & Enrollment of beneficiaries \\
\hline January 2010 & First payments made to beneficiary households \\
\hline July - September 2011 & Midline survey and first round of qualitative data collection \\
\hline August - October 2012 & Endline survey \\
\hline July - August 2013 & Second round of qualitative data collection \\
\hline
\end{tabular}

\section{Data and Outcomes}

In each of the three survey rounds, we collected individual-level data on total health clinic visits in the last year, ${ }^{8}$ ownership of protective footwear (shoes and slippers) by children, health (whether an individual was ill in the last month, and for how many days in the last month they were unable to perform their normal daily activities due to illness), reported ability to perform ordinary activities (doing vigorous activity, walking uphill, bending over or stooping, walking more than one $\mathrm{km}$, walking more than 100 meters, or using a bath or toilet), anthropometrics (height, weight, middle upper-arm circumference, and z-scores for height-for-age, weight-for-age, weight-for-height, and body mass index-for-age), and, for those ill in the last month, the location where medical care was sought (no treatment sought, public dispensary, public hospital, public health center, private pharmacy, traditional healer, private dispensary/hospital/clinic, or mission dispensary/hospital). ${ }^{9}$ Among those seeking treatment, we further gathered data on healthcare financing methods (free treatment, loans, cash or assets, or health insurance). We also collected householdlevel data on expenditure on formal insurance ${ }^{10}$ and, at endline, whether the household participates in the CHF.

8 We lack data on whether such visits were for preventive or curative purposes and only know the total.

9 Data on protective footwear were only collected for children aged 0-18, data on anthropometrics for children aged 0-5, and data on ordinary activities for those aged 60 and over. Individuals sick in the last month were asked to report the primary health provider and payment method for their main health problem.

10 Insurance expenditure data are not further disaggregated by type of insurance. 


\section{Methods and Empirical Strategy}

\section{Empirical Specification}

We carried out follow-up surveys in 2011 and in 2012 to capture both short-term (1.5 years) and mediumterm ( 2.5 years) impacts of the program. Given random assignment to treatment, we recover causal intentto-treat estimates from the following empirical specification:

$$
h_{i t}=\beta_{0}+\beta_{1} 2011_{t}+\beta_{2} 2012_{t}+\delta_{1} T_{i} \times 2011_{t}+\delta_{2} T_{i} \times 2012_{t}+\alpha_{i}+\epsilon_{i t}
$$

where $i$ indexes individuals and $t$ indexes the survey round. $h_{i t}$ is a health-related outcome, $\alpha_{i}$ are individual fixed effects, $T_{i}=1$ in a village assigned to treatment and zero otherwise, $2011_{t}=1$ at the time of the midline survey (July-September 2011) and zero otherwise, and 2012 ${ }_{t}=1$ at the time of the endline (August-October 2012) and zero otherwise. When we consider a household-level outcome, $i$ instead indexes households and $\alpha_{\mathrm{i}}$ are household fixed effects.

In treatment villages, 9.0 percent of households did not receive treatment, likely due to last-minute changes in community prioritization or household refusal. In control villages, 0.6 percent of households received treatment, likely due to their proximity to a treatment village. As a result, our intent-to-treat estimates represent a lower bound on the actual impact of receiving transfers. We also estimate the effect of treatment on the treated by using the fitted values from a regression of treatment on assignment to treatment in place of $T_{i}$ in equation $1 .^{11}$

\section{Heterogeneous Treatment Effects Examined}

We estimate the overall impacts of the CCT program as well as its impacts on several subgroups. First, we examine impacts by age group. As health conditions applied only to children aged 0-5 and elderly aged 60 and over, and given that each of these two age groups has a different set of health issues and faced different conditions under the CCT program, it is instructive to examine program impacts on them separately. Overall impacts are for all individuals in the surveyed households, not only all individuals in the two subgroups.

Second, for two central outcomes likely to be heavily influenced by the quality of available healthcarehealth clinic visits and health during the last month-we examine heterogeneous impacts of the CCT program by baseline health clinic staff (the sum of doctors, nurses, and other assistants) per capita. Specifically, we divide villages into two types: those with above-median and below-median health clinic staff per capita at baseline. This helps us assess if improvements are sensitive to capacity constraints.

Finally, for outcomes likely to be influenced by how credit-constrained a household is-shoes and slipper ownership, expenditure on insurance, participation in the CHF, whether one treats illness and where (public or private facilities of various types), and how one finances treatment-we examine heterogeneous impacts by baseline household asset wealth. This allows us to observe how the program affects the moderately poor (top half of beneficiaries in terms of asset wealth) versus the extremely poor (bottom half). To capture asset wealth, we carry out a principal components analysis (PCA) using dummy variables for ownership of 13 assets. ${ }^{12}$

\section{Outcome of the Randomization}

A comparison of baseline sample means in treatment and control villages reveals balance on most outcomes (table S1, panel A, in the supplementary online appendix). Across 41 outcomes, for only six (three) are there significant differences at the ten percent (five percent) level. Supplementary online appendix table S1, panel B shows similar balance on individual and household demographic characteristics and

11 We use the Stata package, xtivreg, written by Schaffer (2010).

12 These include whether the household owns an iron, refrigerator, television, mattress or bed, radio, watch or clock, sewing machine, stove, bicycle, motorcycle, car or truck, wheelbarrow or cart, and mobile phone. We take as our index the first principal component emerging from this analysis. 
village characteristics. The only significant difference is that treatment households are less likely to have an improved floor. We use individual (or household, for outcomes that vary at that level) fixed effects to account for baseline imbalances. ${ }^{13}$

\section{Attrition}

If attrition were correlated with treatment status, one might worry that attrition had compromised the internal validity of the results. ${ }^{14}$ Fortunately, this is not the case, as shown in table S2. Columns (1)-(4) consider household attrition, columns (5)-(8) consider individual attrition, and columns (9)-(12) consider individual attrition for those for whom health conditions applied (children aged 0-5 and those aged 60 and over). For each of the three analyses, we consider attrition at midline and at endline. In no case does the treatment dummy significantly predict attrition. F-statistics for the joint significance of the treatment dummy and the interaction terms further indicate that these coefficients are never jointly significant. Overall, we conclude that attrition does not affect the internal validity of our results.

\section{Results}

\section{Health Clinic Visits}

At baseline, the average $0-5$ year old visited a clinic 8.3 times per year (compared to the program condition of six visits), and the average individual aged 60 or older visited 2.8 times (compared to the program condition of one visit). This reveals that on average, individuals were exceeding program conditions at baseline. ${ }^{15}$ Universal compliance with the program could thus occur at follow-up even with a zero net increase in clinic visits if more frequent visits by those not previously in compliance were offset by less frequent visits by those already complying at baseline. In table 2, we examine the impact of the CCT

Table 2. Effects of Treatment on Health Clinic Visits in the Last 12 Months

\begin{tabular}{|c|c|c|c|}
\hline & $\begin{array}{l}\text { Full sample } \\
\text { (1) }\end{array}$ & $\begin{array}{c}0-5 \text { years old } \\
\text { (2) }\end{array}$ & $\begin{array}{c}60 \text { and over } \\
\text { (3) }\end{array}$ \\
\hline Treatment $\times 2011$ (midline) & & $\begin{array}{l}2.296^{* *} \\
(0.872)\end{array}$ & $\begin{array}{l}1.083^{* * * *} \\
(0.349)\end{array}$ \\
\hline Treatment × 2012 (endline) & $\begin{array}{r}-0.067 \\
(0.253)\end{array}$ & $\begin{array}{c}-1.042 \\
(0.875)\end{array}$ & $\begin{array}{c}0.161 \\
(0.344)\end{array}$ \\
\hline 2011 (midline) & & $\begin{array}{c}-3.817^{* * *} \\
(0.584)\end{array}$ & $\begin{array}{c}-1.214^{* * *} \\
(0.216)\end{array}$ \\
\hline 2012 (endline) & $\begin{array}{c}-1.436^{* * * *} \\
(0.182)\end{array}$ & $\begin{array}{c}-5.762^{* * *} \\
(0.635)\end{array}$ & $\begin{array}{c}-0.670^{* * *} \\
(0.237)\end{array}$ \\
\hline$R^{2}$ & 0.061 & 0.375 & 0.018 \\
\hline Baseline mean & 2.802 & 8.272 & 2.783 \\
\hline Observations & 13713 & 1243 & 5692 \\
\hline
\end{tabular}

Source: Authors' calculations based on 2009, 2011, and 2012 household survey data.

Notes: Treatment estimates are estimates of the effect of living in a treatment village (intent to treat). Midline data are excluded from the full sample because health facility visit data were not collected in the midline survey for those 5-60 years old. Ages refer to age at the time of the baseline survey. Fewer refers to those residing in villages in the bottom half of the distribution of baseline health clinic staff per capita, while more refers to those in the top half. All specifications include individual fixed effects. Standard errors are in parentheses and clustered at the village level. $* *$ indicates $\mathrm{p}<0.01 ; *$ indicates $\mathrm{p}<0.05$; and $*$ indicates $\mathrm{p}<0.10$.

13 In the case of anthropometric outcomes, we use village $\times$ cohort fixed effects. These results are robust to instead using individual fixed effects.

14 Between baseline and midline, 8.6 percent of households attrited from the sample, and, between baseline and endline, 13.2 percent of households attrited.

15 At baseline, 59 percent of children aged 0-5 and 65 percent of those aged 60 and over met or exceeded required health clinic visits, making program conditions nonbinding for them. 
program on the number of health clinic visits in the last year. We focus on overall impacts, impacts on children aged $0-5$, and impacts on those age 60 and over. (At endline, we have clinic visit data for all individuals while, at midline, we only have it for these two groups.)

At midline (1.5 years after treatment began), treatment led to 2.3 more visits (preventive or curative) per year for children aged 0-5 (column 2) and 1.1 more visits per year for those aged 60 and over (column 3). Relative to the baseline mean number of visits for each age group, these represent increases of 28 and 39 percent, respectively, which are comparable to findings in the literature (Levy and Ohls 2007, Akresh et al. 2014). These statistically significant effects, however, disappear at endline (2.5 years after treatment began) for both age groups. ${ }^{16}$ The results are robust to instead estimating a Poisson model that accounts for health clinic visits being a count data outcome (supplementary online appendix table S3) ${ }^{17}$ and to instead estimating the impact of treatment on the treated (supplementary online appendix table S4).

In table 3, we examine the impact of the CCT program on the rate of compliance with annual clinic visits conditions. While we lack administrative data on clinic visits, comparing self-reported visits over the last 12 months with program conditions for total annual visits is instructive. The conditions required six visits for those under age two and one visit for those over age 60; those 2-5 years old needed six visits at the time of the midline but two visits at the time of the endline. We see that treatment increased compliance with program conditions among both those 0-5 years old and those over age 60 at midline. By endline, however, treatment increased compliance with program conditions only among those over age 60 , and not among children aged $0-5$.

Table 3. Effects of Treatment on Compliance with Health Clinic Visits in the Last 12 Months

\begin{tabular}{|c|c|c|c|}
\hline & $\begin{array}{c}\text { Full sample } \\
\text { (1) }\end{array}$ & $\begin{array}{c}0-5 \text { years old } \\
\text { (2) }\end{array}$ & $\begin{array}{c}60 \text { and over } \\
\text { (3) }\end{array}$ \\
\hline Treatment $\times 2011$ (midline) & & $\begin{array}{l}0.288 * * * \\
(0.085)\end{array}$ & $\begin{array}{l}0.259 * * * \\
(0.031)\end{array}$ \\
\hline Treatment $\times 2012$ (endline) & $\begin{array}{l}0.039 * * \\
(0.016)\end{array}$ & $\begin{array}{c}0.019 \\
(0.058)\end{array}$ & $\begin{array}{l}0.086 * * \\
(0.035)\end{array}$ \\
\hline 2011 (midline) & & $\begin{array}{c}-0.086 \\
(0.067)\end{array}$ & $\begin{array}{c}-0.120 * * * \\
(0.026)\end{array}$ \\
\hline 2011 (endline) & $\begin{array}{c}0.020 \\
(0.012)\end{array}$ & $\begin{array}{l}0.186^{* * *} \\
(0.044)\end{array}$ & $\begin{array}{c}-0.010 \\
(0.027)\end{array}$ \\
\hline$R^{2}$ & 0.010 & 0.074 & 0.027 \\
\hline Observations & 13,713 & 1,243 & 5,692 \\
\hline Baseline mean & 0.831 & 0.591 & 0.653 \\
\hline
\end{tabular}

Sources: Authors' calculations based on 2009, 2011, and 2012 household survey data.

Notes: Treatment estimates are estimates of the effect of living in a treatment village (intent to treat). To be in health compliance, those aged $0-5$ years must have 6 clinic visits in last 12 months; those $60+$ must have 1 clinic visit in the last 12 months. At endline (2012), the condition was loosened from 6 to 2 visits for those aged 2-5 years. Midline data are excluded from the full sample because health facility visit data were not collected in the midline survey for those 5-60 years old. Ages refer to age at the time of the baseline survey. All specifications include individual fixed effects. Standard errors are in parentheses and clustered at the village level. $* *$ indicates $\mathrm{p}<0.01 ; *$ indicates $\mathrm{p}<0.05$; and $*$ indicates $\mathrm{p}<0.10$.

Several caveats and observations are warranted. First, households in control villages that by endline anticipated receiving the program within a few months may have increased clinic visits preemptively for fear of somehow being cut from the list of targeted households. Indeed, when we consider compliance with clinic visit as our outcome (table 3), we find a positive and highly statistically significant coefficient

16 At endline, those in treatment villages were still receiving the CCT program and expected it to continue indefinitely. Those in control villages anticipated being enrolled within the next few months (by late 2012).

17 Results hold whether we use heteroskedasticity robust or bootstrapped standard errors. 
on the endline dummy for those $0-5$ years old, consistent with an overall increase in childrens' compliance with program conditions across both treatment and control villages at endline. Second, it is important to interpret these findings in light of high baseline rates of compliance that made the health visit conditions non-binding for many. ${ }^{18}$ Program emphasis on clinic visits may have increased the salience of health services and led households to initially increase visits despite the average household already satisfying visit conditions. Subsequently_by endline-individuals' understanding of the conditions may have improved, and they may have reduced visits to only those they deemed truly necessary, still exceeding the program conditions on average. Third, health improvements due to the program that were realized by endline but not at midline, detailed in section 4, may have reduced demand for clinic visits by endline. Finally, while we lack data on clinic service quality, it may have improved by endline, requiring fewer visits to receive similar care (e.g., receiving more and better services at a first visit could preclude the need for a follow-up visit). We present further evidence and discussion of why clinic visits may have increased at midline but were subsequently unaffected at endline in section 5 .

\section{Protective Footwear}

While health clinic visits are an important aspect of individual investment in health, investments that individuals make to prevent health problems from occurring are also important. We examine the impacts of treatment on ownership of two types of protective footwear: shoes and "slippers" (i.e., open-toed footwear). Table 4 shows that the CCT program led to a significant 18 percentage point increase in shoe ownership among $0-18$ year old children by midline that persisted at endline (column 1). ${ }^{19}$ A null impact on slipper ownership at midline changed to a significant eight percentage point increase by endline (column 2). This suggests that the program did not lead to a substitution between shoes and slippers but, rather, increased take-up of both products by endline. Further, impacts were largest for ownership of shoes, which provide better protection. These impacts are remarkable considering baseline ownership rates of shoes and slippers were 42 percent and 63 percent, respectively.

\section{Health Insurance}

We also examined program impacts on take-up of health insurance. As we discuss in section 1, participation in Tanzania's government-run health insurance program, the CHF, should not only help households cope with the risk of health shocks, but also reduce out-of-pocket expenditures on health given crosssubsidies built into the scheme, favoring the rural poor. Table 4 shows that treatment increased household expenditures on insurance sixfold by midline and eightfold by endline (column 3). It also increased participation in the CHF; while we lack baseline data on participation rates by endline, households in treatment villages were 36 percentage points more likely to participate than were households in control villages (column 4). This is strikingly large given that, at baseline, only three percent of individuals who sought treatment for illness in the last month reported using health insurance to fund it.

Table 5 examines the health care financing methods of individuals who reported being ill in the last month and treated the illness. ${ }^{20}$ We find that, at midline, the program reduced payment for health care using cash or an asset by 18 percentage points, which is a 27 percent decrease from the baseline mean of

18 While nonbinding conditions make a CCT similar to a UCT or LCT, the introduction discusses how UCTs are prevalent, and many CCTs have soft conditions. Thus, our study context is not atypical.

19 Estimates of the effect of treatment on the treated are similar (supplementary online appendix table S5).

20 In supplementary online appendix table S6, we examine whether treatment affects selection into who reports being ill or injured in the last month. We find that few interactions of individual and household characteristics with treatment are statistically significant predictors of illness or injury. Further, when we conduct a test of the joint significance of these interaction terms for individuals for whom health conditions applied (those aged 0-5 and aged 60 and over), we find insignificance at both midline $(\mathrm{p}=0.369)$ and endline $(\mathrm{p}=0.612)$. 
Table 4. Effects of Treatment on Take-Up of Health-Related Products

\begin{tabular}{|c|c|c|c|c|}
\hline & $\begin{array}{c}\text { Dummy - owns } \\
\text { shoes } \\
(1)\end{array}$ & $\begin{array}{l}\text { Dummy - owns } \\
\text { slippers } \\
\text { (2) }\end{array}$ & $\begin{array}{c}\text { Insurance } \\
\text { expenditures } \\
\text { (3) }\end{array}$ & $\begin{array}{c}\text { Dummy - participates } \\
\text { in the CHF } \\
\text { (4) }\end{array}$ \\
\hline Treatment $\times 2011$ (midline) & $\begin{array}{l}0.180^{\text {F** }} \\
(0.043)\end{array}$ & $\begin{array}{c}0.054 \\
(0.035)\end{array}$ & $\begin{array}{l}1.176^{* * *} \\
(0.252)\end{array}$ & \\
\hline Treatment $\times 2012$ (endline) & $\begin{array}{l}0.179^{\ldots \ldots *} \\
(0.047)\end{array}$ & $\begin{array}{l}0.084^{* * *} \\
(0.038)\end{array}$ & $\begin{array}{l}1.516^{\text {w** }} \\
(0.284)\end{array}$ & $\begin{array}{l}0.357^{\text {**** }} \\
(0.039)\end{array}$ \\
\hline 2011 (midline) & $\begin{array}{l}0.129^{\ldots * *} \\
(0.028)\end{array}$ & $\begin{array}{l}0.188^{* * *} \\
(0.023)\end{array}$ & $\begin{array}{l}0.177^{* * *} \\
(0.051)\end{array}$ & \\
\hline 2012 (endline) & $\begin{array}{l}0.126^{\text {w* }} \\
(0.031)\end{array}$ & $\begin{array}{l}0.196^{* * *} \\
(0.028)\end{array}$ & $\begin{array}{l}0.438^{* * * *} \\
(0.099)\end{array}$ & \\
\hline$R^{2}$ & 0.105 & 0.107 & 0.118 & 0.317 \\
\hline Baseline mean & 0.423 & 0.632 & 0.181 & \\
\hline Observations & 6847 & 6847 & 5036 & 1555 \\
\hline
\end{tabular}

Sources: Authors' calculations based on 2009, 2011, and 2012 household survey data.

Notes: Treatment estimates are estimates of the effect of living in a treatment village (intent to treat). Shoe and slipper ownership are individual-level outcomes for those under 18 years old at the time of the baseline survey. Insurance expenditures and Community Health Fund (CHF) participation are household level outcomes. Insurance expenditures refer of total annual medical, car, and life insurance expenditures (thousands of Tanzanian shillings). Data on participation in the CHF are only available from the endline survey. Households that report having never heard of the CHF are assumed to not be participating in the CHF. Columns (1) and (2) include individual fixed effects. Column (3) includes household fixed effects. Column (4) includes baseline controls of age, age, sex, and education level of the household head. Also included are dummies for district, household size, having an improved roof, having an improved toilet, having an improved floor, having piped water, village population, the number of years since the CHF began operating in respondent's village, and the first principal component from a PCA using information on ownership of 13 household assets. Standard errors are in parentheses and clustered at the village level. *** indicates $\mathrm{p}<0.01 ; *$ indicates $\mathrm{p}<0.05$; and ${ }^{*}$ indicates $\mathrm{p}<0.10$.

Table 5. Effects of Treatment on Method Used to Finance Healthcare when Addressing Main Health Problem of the Last Month

\begin{tabular}{|c|c|c|c|c|}
\hline & $\begin{array}{l}\text { Free treatment } \\
\text { (1) }\end{array}$ & $\begin{array}{l}\text { Loan or assistance } \\
\text { (2) }\end{array}$ & $\begin{array}{c}\text { Cash or asset } \\
\text { (3) }\end{array}$ & $\begin{array}{l}\text { Health insurance } \\
\text { (4) }\end{array}$ \\
\hline Treatment $\times 2011$ (midline) & $\begin{array}{c}0.038 \\
(0.052)\end{array}$ & $\begin{array}{r}-0.017 \\
(0.034)\end{array}$ & $\begin{array}{l}-0.176^{* * *} \\
(0.062)\end{array}$ & $\begin{array}{l}0.155^{* * *} \\
(0.049)\end{array}$ \\
\hline Treatment $\times 2012$ (endline) & $\begin{array}{r}-0.083^{*} \\
(0.048)\end{array}$ & $\begin{array}{r}-0.013 \\
(0.032)\end{array}$ & $\begin{array}{c}-0.182^{* \ldots *} \\
(0.065)\end{array}$ & $\begin{array}{l}0.278^{* * *} \\
(0.052)\end{array}$ \\
\hline 2011 (midline) & $\begin{array}{r}-0.007 \\
(0.035)\end{array}$ & $\begin{array}{l}-0.071^{* * *} \\
(0.027)\end{array}$ & $\begin{array}{c}0.054 \\
(0.037)\end{array}$ & $\begin{array}{c}0.024 \\
(0.015)\end{array}$ \\
\hline 2012 (endline) & $\begin{array}{c}0.027 \\
(0.037)\end{array}$ & $\begin{array}{l}-0.074^{* * *} \\
(0.023)\end{array}$ & $\begin{array}{c}0.007 \\
(0.039)\end{array}$ & $\begin{array}{l}0.040^{* * *} \\
(0.013)\end{array}$ \\
\hline$R^{2}$ & 0.009 & 0.035 & 0.022 & 0.142 \\
\hline Baseline mean & 0.216 & 0.103 & 0.654 & 0.027 \\
\hline Observations & 5365 & 5365 & 5365 & 5365 \\
\hline
\end{tabular}

Sources: Authors' calculations based on 2009, 2011, and 2012 household survey data.

Notes: Treatment estimates are estimates of the effect of living in a treatment village (intent to treat). Health problem of the last month refers to the last four weeks. Over the three rounds of the survey, respondents reported being sick or injured a total of 5,922 times. For 5,409 of these reports, the main treatment financing method was reported. 44 people were excluded from this analysis for reporting financing with either "other" or "differed by provider" since it was not possible to understand how these individuals financed treatment. All specifications include individual fixed effects. Standard errors are in parentheses and clustered at the village level. $* *$ indicates $\mathrm{p}<0.01 ; *$ indicates $\mathrm{p}<0.05$; and $*$ indicates $\mathrm{p}<0.10$.

65 percent. This same effect size was sustained at endline. Those no longer financing treatment with cash and assets began using health insurance; we see a 16 percentage point increase in use of health insurance at midline to finance treatment, which swelled to 28 percentage points by endline (from a baseline mean of only 2.7 percent). 
Our findings on health insurance may be driven by several factors. First, if liquidity has been a binding constraint, a CCT program may increase take-up of insurance. ${ }^{21}$ Second, the CCT program may have improved access to information about the $\mathrm{CHF}$ and lowered barriers to enrollment. In qualitative data, health clinic staff in treatment villages reported going to the place where beneficiaries collected transfers to tell them about the CHF and encourage sign-up while they still felt rich (Evans et al. 2014). Finally, other research on the same CCT finds that it increased familiarity with and trust in local leaders and health care providers (Evans et al. 2017). Combined with evidence that trust increases take-up of insurance (Dercon et al. 2015), this too may explain increased participation in the CHF.

\section{Health}

Table 6 reports the effects of treatment on two key health outcomes: whether or not an individual was ill or injured in the last month, and the number of days that the individual was unable to perform their normal daily activities in the last month due to illness (sick days). These capture, respectively, the extensive and intensive margins of illness. We see that, at midline, treatment had no significant impact on either health outcome. However, at endline treatment significantly reduced both the extensive and intensive margins of illness. In particular, for the sample as a whole, treatment resulted in a 4.3 percentage point reduction in the incidence of illness or injury in the last month ( $\mathrm{p}$-value $=0.101)$; while of borderline statistical significance, this is a sizeable 17 percent decrease relative to the baseline mean incidence of 27.6 percent. When we instead compute the effect of treatment on the treated (supplementary online appendix table S7), we observe a statistically significant $(\mathrm{p}<0.10), 4.6$ percentage point reduction in incidence of illness or injury in the last month. For the sample as a whole, treatment also resulted in a statistically significant, nearly half-day decrease in sick days in the last month (a 27 percent decrease relative to the baseline mean of 1.64 sick days). These treatment effects seem to be strongly driven by health improvements for young children (ages 0-5), for whom the reduction in incidence of illness in the last month is 10.7

Table 6. Effects of Treatment on IIIness and Injury in the Last Month

\begin{tabular}{|c|c|c|c|c|c|c|}
\hline & \multicolumn{3}{|c|}{ Dummy - ill or injured in last month } & \multicolumn{3}{|c|}{$\begin{array}{l}\text { Days in last month unable to perform normal daily } \\
\text { activities due to illness or injury }\end{array}$} \\
\hline & $\begin{array}{l}\text { Full sample } \\
\text { (1) }\end{array}$ & $\begin{array}{l}0-5 \text { years old } \\
\text { (2) }\end{array}$ & $\begin{array}{l}60 \text { and over } \\
\text { (3) }\end{array}$ & $\begin{array}{l}\text { Full sample } \\
\text { (4) }\end{array}$ & $\begin{array}{l}0-5 \text { years old } \\
(5)\end{array}$ & $\begin{array}{l}60 \text { and over } \\
(6)\end{array}$ \\
\hline Treatment $\times 2011$ (midline) & $\begin{array}{c}0.004 \\
(0.026)\end{array}$ & $\begin{array}{r}-0.011 \\
(0.055)\end{array}$ & $\begin{array}{c}0.044 \\
(0.040)\end{array}$ & $\begin{array}{r}-0.210 \\
(0.225)\end{array}$ & $\begin{array}{r}-0.122 \\
(0.285)\end{array}$ & $\begin{array}{r}-0.204 \\
(0.489)\end{array}$ \\
\hline Treatment $\times 2012$ (endline) & $\begin{array}{r}-0.043 \\
(0.026)\end{array}$ & $\begin{array}{r}-0.107^{*} \\
(0.063)\end{array}$ & $\begin{array}{r}-0.002 \\
(0.035)\end{array}$ & $\begin{array}{r}-0.435^{*} \\
(0.220)\end{array}$ & $\begin{array}{c}-0.758^{* *} \\
(0.358)\end{array}$ & $\begin{array}{r}-0.353 \\
(0.414)\end{array}$ \\
\hline 2011 (midline) & $\begin{array}{c}0.002 \\
(0.018)\end{array}$ & $\begin{array}{r}-0.054^{*} \\
(0.032)\end{array}$ & $\begin{array}{c}0.032 \\
(0.028)\end{array}$ & $\begin{array}{c}0.198 \\
(0.165)\end{array}$ & $\begin{array}{r}-0.206 \\
(0.170)\end{array}$ & $\begin{array}{l}0.675^{* * *} \\
(0.323)\end{array}$ \\
\hline 2012 (endline) & $\begin{array}{l}0.078^{* * *} \\
(0.016)\end{array}$ & $\begin{array}{c}0.031 \\
(0.047)\end{array}$ & $\begin{array}{l}0.147^{* \ldots *} \\
(0.023)\end{array}$ & $\begin{array}{l}1.076^{* \ldots *} \\
(0.147)\end{array}$ & $\begin{array}{c}0.298 \\
(0.297)\end{array}$ & $\begin{array}{l}2.389^{* * * *} \\
(0.269)\end{array}$ \\
\hline$R^{2}$ & 0.006 & 0.010 & 0.024 & 0.012 & 0.011 & 0.033 \\
\hline Baseline mean & 0.276 & 0.282 & 0.388 & 1.636 & 1.052 & 2.786 \\
\hline Observations & 20741 & 1537 & 5694 & 20740 & 1537 & 5693 \\
\hline
\end{tabular}

Sources: Authors' calculations based on 2009, 2011, and 2012 household survey data.

Notes: Treatment estimates are estimates of the effect of living in a treatment village (intent to treat). Illness in the last month refers to the last four weeks. Ages refer to age at the time of the baseline survey. All specifications include individual fixed effects. Standard errors are in parentheses and clustered at the village level. $* *$ indicates $\mathrm{p}<0.01 ; *$ indicates $\mathrm{p}<0.05$; and $*$ indicates $\mathrm{p}<0.10$.

21 A desire to ensure against health shocks can be understood in light of the frequency of such shocks in our study context; at baseline, 55 percent of households reported experiencing a health shock in the last five years (specifically, a chronic or severe illness or accident of a household member, or a death in the family). 
percentage points (significant at the ten percent level) and the reduction in sick days is 0.76 (significant at the five percent level). We find no significant overall program impacts for those aged 60 and over either on the extensive or the intensive margins. ${ }^{22}$ Similar results hold when we instead estimate a Poisson model (supplementary online appendix table S3). While the program has health benefits, these take time to materialize, are most prominently on the intensive rather than extensive margin of illness, and accrue predominately to young children.

Despite health improvements, the CCT program did not change the ordinary activities that elderly individuals could perform, as shown in supplementary online appendix table S10. Specifically, it did not have significant impacts on individuals' reported ability to do five out of six, nor did it affect a simple 0-6 index of these activities (the "ordinary activities index"). One exception is the ability to walk more than 100 meters (a dummy that had a very high baseline mean of 0.96 ); there, we find a very small negative impact of the program at endline. Overall, however, the program did not have systematic impacts on the types of activities that individuals could perform; rather, it changed the number of days that they could perform their activities.

There are several reasons that health may have improved. First, given that the CCT program increased health clinic visits at midline, this increased health-seeking behavior may have itself improved health by endline. Second, additional income, insurance, and the added familiarity with health clinics generated by the program may have spurred individuals to visit clinics promptly whenever ill, thus reducing the duration of illness. If clinic visits were better timed (even if their aggregate numbers did not increase), this might explain why our results on the intensive margin of illness are the most robust. Third, the program may have generally stimulated health-promoting investments by households. Existing research on the CCT program shows that it did not increase food consumption during the last week at either midline or endline, but that it did increase expenditures on non-food items in the last 12 months, including on women's and children's clothing, and increased the number of goats and chickens households owned (Evans et al. 2014). Further, the program increased children's shoe ownership. In section 5, we present further evidence and discussion on why health may have improved by endline but not midline, and what role program health conditions may have played in delivering health benefits.

\section{Anthropometrics}

Supplementary online appendix table S11 reports the effects of treatment on a number of anthropometric outcomes for children aged 0-5: height-for-age, weight-for-age, weight-for-height, body mass index (BMI)for-age, height, weight, and middle upper-arm circumference (MUAC) (columns 1-7, respectively). These regressions use $\times 6$-month age cohort fixed effects since very few children were in the $0-5$ age range for multiple observations during 2009-2012. We find no evidence that treatment influences these outcomes. ${ }^{23}$ The lack of anthropometric effects is striking; it contributes to a mixed literature on the impacts of CCTs on child anthropometrics (Fiszbein and Schady 2009). The result is less surprising when considering the null impacts of the program on food consumption (Evans et al. 2014).

\section{Healthcare Provider Type}

Table 7 examines the impacts of the CCT program on healthcare provider decisions of individuals who reported being ill in the last month. ${ }^{24}$ Individuals either fail to treat their main health problem (15 percent

22 Treatment did not affect rates of mortality or the number of household members in different age groups (supplementary online appendix tables S8, S9, and panel C of supplementary online appendix table S3).

23 We also find null results when only considering children under age 2. Additionally, we still get null results when we flexibly control for child age with a cubic functional form; these results are available upon request, and ensure that natural variation in z-scores over the age of the child is not biasing our estimates.

24 At baseline, 28 percent of individuals reported being ill or injured in the last month; 85 percent sought treatment for their illness, 49 percent in the public sector and 36 percent in the private sector. 
Table 7. Effects of Treatment on Type of Health Provider Visited to Address Main Health Problem of the Last Month

\begin{tabular}{|c|c|c|c|c|c|c|c|c|}
\hline & \multicolumn{4}{|c|}{ Public } & \multicolumn{4}{|c|}{ Private } \\
\hline & $\begin{array}{l}\text { None } \\
\text { (1) }\end{array}$ & Dispensary & $\begin{array}{l}\text { District, } \\
\text { region, or } \\
\text { referral hospital } \\
(3)\end{array}$ & $\begin{array}{l}\text { Health } \\
\text { center } \\
\text { (4) }\end{array}$ & $\begin{array}{l}\text { Pharmacy } \\
\text { or chemist } \\
\text { (5) }\end{array}$ & $\begin{array}{l}\text { Healer, } \\
\text { herbalist, or } \\
\text { faith healer } \\
\text { (6) }\end{array}$ & $\begin{array}{c}\text { Dispensary, } \\
\text { hospital, } \\
\text { clinic, or store } \\
\text { (7) }\end{array}$ & $\begin{array}{c}\text { Mission } \\
\text { dispensary } \\
\text { or hospital } \\
\text { (8) }\end{array}$ \\
\hline Treatment $\times 2011$ (midline) & $\begin{array}{c}-0.119^{\text {3. }} \\
(0.041)\end{array}$ & $\begin{array}{l}0.174^{* * *} \\
(0.048)\end{array}$ & $\begin{array}{r}-0.036 \\
(0.024)\end{array}$ & $\begin{array}{c}0.001 \\
(0.025)\end{array}$ & $\begin{array}{r}-0.035 \\
(0.040)\end{array}$ & $\begin{array}{c}0.024 \\
(0.016)\end{array}$ & $\begin{array}{r}-0.007 \\
(0.017)\end{array}$ & $\begin{array}{r}-0.002 \\
(0.008)\end{array}$ \\
\hline Treatment $\times 2012$ (endline) & $\begin{array}{c}-0.054 \\
(0.037)\end{array}$ & $\begin{array}{l}0.148^{* * *} \\
(0.050)\end{array}$ & $\begin{array}{r}-0.003 \\
(0.029)\end{array}$ & $\begin{array}{r}-0.021 \\
(0.026)\end{array}$ & $\begin{array}{c}-0.055 \\
(0.047)\end{array}$ & $\begin{array}{r}-0.010 \\
(0.022)\end{array}$ & $\begin{array}{r}-0.001 \\
(0.019)\end{array}$ & $\begin{array}{r}-0.004 \\
(0.014)\end{array}$ \\
\hline 2011 (midline) & $\begin{array}{l}0.100^{3 * *} \\
(0.032)\end{array}$ & $\begin{array}{r}-0.033 \\
(0.035)\end{array}$ & $\begin{array}{c}0.010 \\
(0.019)\end{array}$ & $\begin{array}{c}0.030 \\
(0.020)\end{array}$ & $\begin{array}{c}-0.066^{* *} \\
(0.034)\end{array}$ & $\begin{array}{r}-0.027^{*} \\
(0.014)\end{array}$ & $\begin{array}{r}-0.011 \\
(0.012)\end{array}$ & $\begin{array}{r}-0.003 \\
(0.004)\end{array}$ \\
\hline 2012 (endline) & $\begin{array}{c}0.005 \\
(0.027)\end{array}$ & $\begin{array}{c}0.053 \\
(0.041)\end{array}$ & $\begin{array}{c}0.017 \\
(0.025)\end{array}$ & $\begin{array}{c}0.029 \\
(0.020)\end{array}$ & $\begin{array}{c}-0.088^{3 *} \\
(0.041)\end{array}$ & $\begin{array}{r}-0.012 \\
(0.017)\end{array}$ & $\begin{array}{r}-0.004 \\
(0.015)\end{array}$ & $\begin{array}{c}0.001 \\
(0.013)\end{array}$ \\
\hline$R^{2}$ & 0.016 & 0.029 & 0.005 & 0.006 & 0.024 & 0.005 & 0.002 & 0.001 \\
\hline Baseline mean & 0.154 & 0.395 & 0.059 & 0.035 & 0.274 & 0.047 & 0.023 & 0.013 \\
\hline Observations & 5889 & 5889 & 5889 & 5889 & 5889 & 5889 & 5889 & 5889 \\
\hline
\end{tabular}

Sources: Authors' calculations based on 2009, 2011, and 2012 household survey data.

Notes: Treatment estimates are estimates of the effect of living in a treatment village (intent to treat). Health problem of the last month refers to the last four weeks. Over the three rounds of the survey, respondents reported being sick or injured a total of 5,922 times. In all of those reports, the most important health provider was reported. 33 people were excluded from this analysis for reporting that the most important health provider was "other." All specifications include individual fixed effects. Standard errors are in parentheses and clustered at the village level. ***indicates $\mathrm{p}<0.01 ; *$ indicates $\mathrm{p}<0.05$; and * indicates $\mathrm{p}<0.10$.

did so at baseline) or visit one of several different types of public and private providers. As the health conditions of the program required visits to be at public facilities, we anticipated finding larger impacts of treatment on public than on private facility visits. We find that, at midline, the program reduced failure to seek treatment by 12 percentage points (column 1). That illness was more likely to be treated may explain why health impacts were most robust on the intensive margin, with the CCT program generally contributing to shorter spells of illness. At both midline and endline, the program increased use of public dispensaries by 17 percentage points at midline and 15 percentage points at endline (column 2). However, it did not impact use of private providers (columns 5-8). This is consistent with the health clinic visit conditions of the program, which counted only visits to public facilities and not private facilities. Rather than drawing individuals from the private to the public sector, we see a shift from a failure to treat illness to treatment at a public dispensary. Further, the program did not lead individuals to treat illness at a public hospital or a health center (columns 3-4). These are larger facilities that would typically offer more services (and potentially more qualified staff), but which are usually further away.

\section{Robustness: Corrections for Multiple Hypothesis Testing}

A growing literature recognizes the risk of finding false positives when testing multiple hypotheses and advances correction methods. Two popular methods are the Benjamini and Hochberg $(\mathrm{BH})$ and the Benjamini-Krieger-Yekutieli (BKY) methods, which control for the false discovery rate (FDR) (Benjamini and Hochberg 1995, Benjamini et al. 2006). We compute the q-values (i.e., p-values corrected for multiple testing) of each. As a third test, we apply a Bonferroni correction, a method of controlling the family-wise error rate (FWER) that involves multiplying each p-value by the number of tests performed. While simple to compute, it suffers from poor power (Anderson 2008) and is often used as an upper bound on the FWER (Hochberg 1988). We thus rely primarily on the BH and BKY results but take the Bonferroni as a useful guide to the lower bound of the significance of our results.

Supplementary online appendix table S12 reports the resulting q-values from the three correction methods for all originally statistically significant impacts. For each method, a group of hypotheses is defined by the follow-up survey round (midline or endline) and broad type of outcome being considered (e.g., child anthropometrics or ordinary activities). This is usually equivalent to grouping together all 
of the hypotheses within a table for a given survey round. ${ }^{25}$ Hypotheses associated with heterogeneous treatment effects are grouped with the hypotheses of overall treatment effects, despite being displayed in separate tables.

In total, we observe 61 statistically significant impacts of the CCT program in the paper's main tables. When we correct for multiple testing using the BKY (BH) method, 45 (43) remain significant. With the more conservative Bonferroni method, 35 remain significant. Our main conclusions still hold.

\section{Mechanisms}

We gain additional insight into the mechanisms likely driving the impacts of treatment by separately examining subgroups of beneficiaries. We already considered impacts by age group. However, as we discuss in section 3, we also consider two additional types of heterogeneous treatment effects. For two central outcomes likely to be heavily influenced by the quality of available healthcare-health clinic visits and health during the last month-we examine heterogeneous impacts on villages with above-median versus below-median health clinic staff per capita at baseline. This helps us assess if improvements are sensitive to capacity constraints. For outcomes likely to be influenced by how credit-constrained a household is-shoes and slipper ownership, expenditure on insurance, participation in the CHF, whether one treats illness and where (public or private facilities), and how one finances treatment-we examine heterogeneous impacts on moderately poor households (top half of beneficiaries in terms of asset wealth) versus extremely poor households (bottom half).

\section{Impacts by Health Clinic Staffing Levels}

When we examine heterogeneous treatment effects by baseline health clinic staff per capita (supplementary online appendix table S13), several interesting findings emerge. First, panel A reveals that we cannot reject the null hypothesis that the CCT program had the same effect on health clinic visits in villages with few baseline health staff per capita (the bottom half of the distribution) as in villages with many (the top half). This is true overall and for both age groups (ages $0-5$ and those age $60+$ ). This provides suggestive evidence that the impacts of treatment on clinic visits would not be enhanced by increasing clinic staff per capita. Second, panel B shows heterogeneous impacts on health by baseline clinic staff per capita. Here, we find that reductions in sick days are concentrated in villages with more health staff per capita with no significant impacts in villages with few staff per capita. For individuals in villages that were highly-staffed at baseline, the average reduction in sick days in the last month is 0.96 (compared to an insignificant 0.07 days in more poorly-staffed villages). The difference between these two effects is statistically significant at the five percent level. This suggests that reductions in the intensive margin of illness may, in fact, be conditional on a village having sufficient staff to attend patients and treat illness. It is important to note, however, that there are no differential impacts of the program by baseline staffing levels on sick days for children aged 0-5. Clinic staffing may matter more for older individuals, possibly as they are less integrated into the health system. Additionally, there are no differential impacts of treatment on the incidence (extensive margin) of illness by clinic staffing levels.

Supplementary online appendix fig. S1 helps illustrate these impacts. Subfigure (a) presents two villagelevel scatterplots-one for midline, one for endline-each with 80 data points: 40 show treatment village averages (in black circles), and 40 show control village averages (in gray squares). We plot on the y-axis the average change in the number of sick days in the last month between baseline and follow-up (positive

25 There are three exceptions. In table 4, protective footwear outcomes are grouped separately from insurance-related outcomes, just as they are separately considered in section 4 . In table 6 , hypotheses related to the extension and intensive margins of health are grouped separately. And in supplementary online appendix table S10, we omit the ordinary activities index from our grouping; estimation of impacts of treatment on an index simply serves as an additional check on the robustness of these null findings. 
numbers indicate an increase, negative a decrease) and on the $\mathrm{x}$-axis village health clinic staff per capita at baseline. We include separate linear fits for treatment and control. At midline, we see that there are essentially no health improvements in either treatment or control villages across the full distribution of clinic staff per capita. By endline, however, treatment villages on average have greater reductions in sick days than do control villages across the full range of values of staff per capita. However, the difference is greatest in villages with especially high staff per capita.

Subfigure (b) of supplementary online appendix fig. S1 presents a similar analysis where the outcome is now the average change in the number of clinic visits in the last year between baseline and follow-up. At midline, treatment villages on average experience larger increases in clinic visits than do control villages across the full range of values of clinic staff per capita. While the difference is greater in villages with higher staff per capita, this difference was not statistically significant in regressions. At endline, we see similar reductions in clinic visits in treatment and control villages across the full distribution of staff per capita, possibly reflecting better average health at endline (as seen in subfigure (a) that alleviated capacity constraints.

\section{Impacts by Household Wealth}

Examining heterogeneous treatment effects by baseline household asset wealth (supplementary online appendix table S14) reveals several interesting results. First, as shown in panel A, we do not find significant differences in the impacts of the program on whether one treats illness (column 1) and whether or not they treat it in a public dispensary (column 2), according to baseline household wealth. ${ }^{26}$ However, panel B shows that the impacts of the CCT program on shoe ownership (column 1), slipper ownership (column 2), and insurance expenditures (column 3) are responsive to baseline household wealth. For each of the three, the impacts of treatment are larger for the extremely poor (those in the bottom half of asset wealth at baseline) than for the moderately poor for both follow-up survey rounds. These differences are in several cases statistically significant. At midline, the extremely poor saw a significantly greater increase in shoe ownership and insurance expenditure than did the moderately poor while, at endline, the extremely poor had a significantly greater increase in slipper ownership than did the moderately poor. The effect on CHF participation at endline is slightly larger (but not statistically significantly different) for extremely poor households (column 4). However, panel C reveals that, while the increase in use of health insurance at endline was larger for the extremely poor than for the moderately poor, the difference is not statistically significant. Overall, these results suggest that not only can a CCT program increase take-up of products that tend to prevent health problems from occurring and help households cope with health-related risks, but also that, in some cases, the poorest of the poor benefit most.

\section{Exploratory Analysis: Timing and Drivers of Health Impacts}

Our findings raise two important and related questions that have not been fully answered: first, why do health improvements show up at endline but not at midline? Second, did clinic conditions contribute to the health improvements realized from the program or were they unnecessary? We carry out exploratory analyses to shed further light on both questions.

Supplementary online appendix fig. S2 presents four village-level scatterplots, each containing 80 data points: 40 showing treatment village averages (in black circles) and 40 showing control village averages (in gray squares) with separate linear fits for each set of 40 . We plot on the y-axis the average change in the number of sick days in the last month between baseline and follow-up (positive numbers indicate an

26 While we find no significant impacts of treatment on other types of providers (columns 3-8), there are two statistically significant differences worth noting. First, at midline, treatment led the moderately poor to increase use of public health centers-although it had no significant impact on their use by the extremely poor. Second, at midline, treatment led the extremely poor to decrease use of private dispensaries, hospitals, clinics, and stores—although it had no significant impact on their use by the moderately poor. 
increase in sick days, negative numbers a decrease). On the $\mathrm{x}$-axis, subfigure (a) has the village average number of clinic visits per person at baseline, while subfigure (b) has the share of the village already complying with the health conditions at baseline. Each subfigure features a plot for each of the two follow-up surveys.

Subfigures (a) and (b) tell a similar story; reductions in the intensive margin of illness (sick days) show up at midline for a subset of the population (even if there are no significant reductions in the aggregate, as shown in our regressions): those already complying with or exceeding program health conditions at baseline and those with more clinic visits at baseline (call these "the compliers"). This suggests that it was not the conditions driving initial (midline) health improvements but was the income effect of the transfer on individuals already visiting clinics frequently. However, by endline, the story reverses. It was those who were not complying with the conditions at baseline and those with fewer clinic visits at baseline (call these "the non-compliers") who saw the greatest reductions in sick days.

Our regressions showed that treatment boosted health clinic visits at midline. Supplementary online appendix fig. S3 further reveals that this midline increase in clinic visits was larger among noncompliers than among compliers. ${ }^{27}$ This suggests that the CCT program helped individuals in two waves. First, compliers experienced a mild reduction in sick days at midline, likely due to income effects of the CCT. Second, noncompliers experienced health benefits, but with a lag. By midline they increased their health clinic visits, likely due to both the conditions of the program and the income from the transfer permitting them to go to the clinic when sick rather than allowing illness to go untreated. But it was not until endline that this resulted in better health. By endline, these noncompliers likely benefited from at least two factors: their increased exposure to clinics at midline and the fact that treatment had already reduced illness in some children in the village (i.e., the compliers), spurring an overall reduction in infectious disease rates that shows up in our regressions as statistically significant overall impacts of treatment on sick days at endline. Supplementary online appendix fig. S2 also reveals that we see larger reductions in sick days at endline among those with fewer clinic visits at baseline (subfigure [a]) and among those with lower rates of compliance with conditions at baseline (subfigure [b]), consistent with conditions helping to explain overall health improvements.

\section{Conclusion}

This paper provides evidence that, after 2.5 years, a conditional cash transfer (CCT) program in Tanzania made children aged 0-5 experience fewer monthly sick days. We find no evidence of health improvements for those age 60 and over despite their having also been required to visit a health clinic as a condition of the transfer, suggesting greater promise of such programs for the young.

The statistically significant improvements in health outcomes after 2.5 years are particularly striking given that the program's initial effect of increasing annual clinic visits had disappeared after 2.5 years of transfers. If health improvements were not driven by increased clinic visits, then what was the cause? Previous analysis suggests that these study households did not significantly increase consumption (Evans et al. 2014). Instead, we show that households used their transfers to reduce the risk of high heathcare costs. Households invested in footwear for their children, which reduces exposure to health risks. Households were substantially more likely to invest in a government-run health insurance program. They went on to utilize that health insurance to finance clinic visits when ill. Although the total number of clinic visits was not higher among beneficiary households, participation in the insurance program meant that those households could attend the clinic when they most needed it rather than letting immediate financial liquidity determine when, in the course of an illness, to visit the clinic. This is consistent with findings from

27 This is also the case at endline, where despite no aggregate increase in clinic visits at endline due to treatment, we see increases for those with low rates of compliance with health conditions at baseline. 
Adhvaryu and Nyshadham (2015), who demonstrate that households that access formal sector malaria treatment in a more timely way have better health outcomes. The number of visits matters only in part; the timing of visits is also crucial, and the insurance program makes that timing more flexible. Furthermore, the initial increase in visits associated with the program may have increased household familiarity and comfort with clinic services. The availability of such health financing instruments and-potentiallyexplicitly making them available at the point of transfer distribution may be important considerations if countries desire to fully reap health gains from cash transfers.

Our analysis of the health impacts of Tanzania's CCT program is not universally positive; while selfreported health measures improved, we do not find enduring impacts on children's anthropometrics. The cash transfers may make children feel better and be more able to carry out daily activities (e.g., attending school and fetching water), but these may not immediately translate into growth, at least not within 2.5 years. However, they suggest a clear increase in reported child wellbeing.

We find some evidence that, overall, health improvements—at least on the intensive margin-are greater in villages with more health workers per capita. In other words, cash transfers can most effectively reduce the number of days individuals are sick when clinics are sufficiently staffed to provide high-quality services. Clear evidence demonstrates that healthier households are likely to have higher incomes, which then drive better health in a virtuous cycle (Strauss and Thomas 1998). The evidence from this study demonstrates that supply-side investments (in health care providers) combined with cash transfers (to permit households to insure against health shocks) may be critical catalysts to that virtuous cycle.

\section{References}

Adhvaryu, A., and A. Nyshadham. 2015. "Returns to Treatment in the Formal Health Care Sector: Evidence from Tanzania." American Economic Journal: Economic Policy 7 (3): 29-57.

Akresh, R., D. de Walque, and H. Kazianga. 2014. Alternative Cash Transfer Delivery Mechanisms: Impacts on Routine Preventative Health Clinic Visits in Burkina Faso. University of Chicago Press. http://www.nber.org/ chapters/c13377.

Anderson, M.L. 2008. "Multiple Inference and Gender Differences in the Effects of Early Intervention: A Reevaluation of the Abecedarian, Perry Preschool, and Early Training Projects.” Journal of the American Statistical Association 103 (484): 1481-95.

Andrews, C., A. Lopez, and J. Baez. 2014. "What are We Learning on Safety Net Impacts? Reviewing Evidence from 2010-2013.” Social Protection Discussion Paper Series, World Bank, Washington, DC.

Attanasio, O., E. Battistin, E. Fitzsimons, and M. Vera-Hernandez. 2005. "How Effective are Conditional Cash Transfers? Evidence from Colombia."

Babbel, B. 2012. "Evaluating Equity in the Provision of Primary Health Care in Tanzania." https://ir.library. oregonstate.edu/xmlui/handle/1957/32933.

Baird, S., J. De Hoop, and B. Özler. 2013. “Income Shocks and Adolescent Mental Health.” Journal of Human Resources 48 (2): 370-403.

Baird, S., C. McIntosh, and B. Özler. 2011. “Cash or Condition? Evidence from a Cash Transfer Experiment.” Quarterly Journal of Economics 126 (4): 1709-53.

Bank of Tanzania. 2015. Interbank Foreign Exchange Market Summaries. https:/www.bot-tz.org/FinancialMarkets/ IFEMsummaries/IFEMsummaries.asp.

Benhassine, N., F. Devoto, E. Duflo, P. Dupas, and V. Pouliquen. 2015. “Turning a Shove into a Nudge? A 'Labeled Cash Transfer' for Education.” American Economic Journal: Economic Policy 7 (3): 86-125.

Benjamini, Y., and Y. Hochberg. 1995. "Controlling the False Discovery Rate: A Practical and Powerful Approach to Multiple Testing.” Journal of the Royal Statistical Society Series B (Methodological) 57 (1): 289-300.

Benjamini, Y., A. M. Krieger, and D. Yekutieli. 2006. “Adaptive Linear Step-Up Procedures that Control the False Discovery Rate.” Biometrika 93 (3): 491-507. 
Biosca, O., and H. Brown. 2014. “Boosting Health Insurance Coverage in Developing Countries: Do Conditional Cash Transfer Programmes Matter in Mexico?" Health Policy and Planning, czt109.

Birn, A.-E., and A. Solórzano. 1999. "Public Health Policy Paradoxes: Science and Politics in the Rockefeller Foundation's HookWorm Campaign in Mexico in the 1920s.” Social Science and Medicine 49 (9): 1197-1213.

Dercon, S., J.W. Gunning, and A. Zeitlin. 2015. "The Demand for Insurance Under Limited Trust: Evidence from a Field Experiment in Kenya."

Duflo, E. 2000. "Child Health and Household Resources in South Africa: Evidence from the Old Age Pension Program." American Economic Review 90 (2): 393-8.

- 2003. "Grandmothers and Granddaughters: Old-Age Pensions and Intrahousehold Allocation in South Africa." World Bank Economic Review 17 (1): 1-25.

Ekman, B. 2004. "Community-Based Health Insurance in Low-Income Countries: A Systematic Review of the Evidence." Health Policy and Planning 19 (5): 249-70.

Evans, D., S. Hausladen, K. Kosec, and N. Reese 2014. Community-Based Conditional Cash Transfers in Tanzania: Results from a Randomized Trial. World Bank Publications.

Evans, D., B. Holtemeyer, and K. Kosec 2017. "If You Give It, Trust Will Come: The Impacts of Community-Managed Cash Transfers." Working Paper.

Fiszbein, A., and N. Schady. 2009. Conditional Cash Transfers: Reducing Present and Future Poverty. Policy Research Report. Washington, DC: World Bank.

Garcia, M., and C.M. Moore. 2012. The Cash Dividend: The Rise of Cash Transfer Programs in Sub-Saharan Africa. Washington, DC: World Bank.

Handa, S., A. Peterman, D. Seidenfeld, and G. Tembo. 2015. "Income Transfers and Maternal Health: Evidence from a National Randomized Social Cash Transfer Program in Zambia.” Health Economics. http://dx.doi.org/10.1002/hec.3136.

Haushofer, J., and J. Shapiro. 2016. "The Short-Term Impact of Unconditional Cash Transfers to the Poor: Evidence from Kenya.” Quarterly Journal of Economics 131 (4): 1973-2042.

Hochberg, Y. 1988. “A Sharper Bonferroni Procedure for Multiple Tests of Significance.” Biometrika 75 (4): $800-2$.

Hoddinott, J. 2010. "Nutrition and Conditional Cash Transfer Programs." In Conditional Cash Transfers in Latin America, edited by M. Adato and J. Hoddinott. Baltimore: Johns Hopkins University Press.

Independent Evaluation Group 2011. Social Safety Nets: An Evaluation of World Bank Support 2000-2010. Washington, DC: Independent Evaluation Group, World Bank Group.

Kamuzora, P., and L. Gilson. 2007. "Factors Influencing Implementation of the Community Health Fund in Tanzania." Health Policy and Planning 22 (2): 95-102.

Leroy, J.L., M. Ruel, and E. Verhofstadt 2009. “The Impact of Conditional Cash Transfer Programmes on Child Nutrition: A Review of Evidence Using a Programme Theory Framework." Journal of Development Effectiveness 1 (2): 103-29.

Levy, D., and J. Ohls. 2007. Evaluation of Jamaica's PATH Program: Final Report. Report prepared.

Macours, K., N. Schady, and R. Vakis. 2012. “Cash Transfers, Behavioral Changes, and the Cognitive Development of Young Children: Evidence from a Randomized Experiment." American Economic Journal: Applied Economics 4 (2): 247-273.

Maluccio, J., and R. Flores. 2005. Impact Evaluation of a Conditional Cash Transfer Program: The Nicaraguan Red de Protección Social. International Food Policy Research Institute.

Marriott, A. 2011. “Does Health Insurance Work in Tanzania?” http://www.globalhealthcheck.org/?p=388.

Mascarini-Serra, L. 2011. "Prevention of Soil-Transmitted Helminth Infection.” Journal of Global Infectious Diseases 3 (2): $175-82$.

Morris, S.S., P. Olinto, R. Flores, E.A. Nilson, and A.C. Figueiro. 2004. “Conditional Cash Transfers are Associated with a Small Reduction in the Rate of Weight Gain of Preschool Children in Northeast Brazil.” Journal of Nutrition 134 (9): 2336-41.

Mtei, G., and J. Mulligan et al. 2007. Community Health Funds in Tanzania: A Literature Review. Ifakara Health Research and Development Centre, Ifakara.

Paxson, C., and N. Schady. 2010. "Does Money Matter? The Effects of Cash Transfers on Child Development in Rural Ecuador.” Economic Development and Cultural Change 59 (1): 187-229. 
Robertson, L., P. Mushati, J.W. Eaton, L. Dumba, G. Mavise, J. Makoni, C. Schumacher, T. Crea, R. Monasch, and L. Sherr et al. 2013. "Effects of Unconditional and Conditional Cash Transfers on Child Health and Development in Zimbabwe: A Cluster-Randomised Trial.” The Lancet 381 (9874): 1283-92.

Schaffer, M. 2010. XTIVREG2: Stata Module to Perform Extended IV/2SLS, GMM and AC/HAC, LIML and k-class Regression for Panel Data Models. http://ideas.repec.org/c/boc/bocode/s456501.html.

Strauss, J., and D. Thomas. 1998. "Health, Nutrition, and Economic Development." Journal of Economic Literature 36 (2): 766-817.

World Health Organization. 2014. United Republic of Tanzania: Health Profile. Africa's Pulse. http://www.who. int/gho/countries/tza.pdf?ua=1. 